\title{
La cátedra de la paz: un escenario emergente de praxis educativa en la
}

\section{Universidad Tecnológica de Pereira ${ }^{1}$}

The chair of peace: an emerging scenario of educational praxis at Universidad Tecnológica de Pereira

\author{
Jefferson Martínez Santa² \\ Martínez S, Jefferson \\ miradas $N^{\circ} 2$ - 2019 ISSN digital N²539-3812 Págs 178 - 196 \\ Recepción: Enero 28 de 2019 \\ Aprobación: Junio 4 de 2019 \\ Publicación: junio 30 de 2019
}

- ¿Qué sueña la paz?

- Acabar con la guerra, pero sin hacerle daño alguno, más bien enseñarle a la guerra las maravillas de la vida.

María, 11 años, Armenia (En

Naranjo, 2015, p.70)

\section{Resumen}

Este artículo presenta una reflexión que deriva de un proceso de investigación con respecto a la implementación de la Cátedra de la Paz de la Universidad Tecnológica de Pereira, que en su apuesta pedagógica y didáctica busca formar sujetos políticos a través de un laboratorio de aprendizaje. Por lo tanto, se parte del testimonio de una de las estudiantes de la asignatura para hacer un ejercicio de interpretación frente a los alcances que ha tenido la cátedra. El texto es el resultado de un estudio de caso, de allí que muestra a partir de un despliegue narrativo un caso particular: el de una estudiante.

1 Artículo derivado del proyecto de investigación: Formación de sujetos políticos desde una experiencia de educación para la paz, avalado por la Vicerrectoría de Investigaciones, Innovación y Extensión de la UTP en la décima convocatoria. Código CIE: 1-17-2.

2 Licenciado en Bilingüismo con Énfasis en Inglés de la Universidad Tecnológica de Pereira. Egresado de la sexta cohorte del Diplomado en Liderazgo por la Paz SUEJE-UTP. Mediador de lectura para niños. Correo: jeffer_95@utp. edu.co 
Palabras claves: Educación para la paz, pedagogía para la paz, subjetividad política, laboratorio de paz

\section{Abstract}

This article presents a reflection that derives from a research process regarding the implementation of the course Cátedra de la Paz at Universidad Tecnológica de Pereira. The course aims at building political subjectivities through a pedagogical and didactic construction that is the learning laboratory. Therefore, this article is based on the analysis of a student's testimony of her experience in the class. This let us approach to the scope of the subject at the university. This text is the result of a case study, so it shows through the narration a particular case: the student's learning experience.

Keywords: Education for peace, pedagogy for peace, political subjectivity, peace laboratory

\section{Introducción}

La conformación oficial de la mesa de negociación entre las FARC-EP y el Gobierno Nacional marcó un hito en la historia de Colombia, que puso sobre la agenda política la paz del país. Para el 2014, las elecciones presidenciales y el clima de la opinión pública mostraron escenarios en los que la paz era el objeto de disputa para ganar el periodo de gobierno 2014-2018. En estas circunstancias, Juan Manuel Santos llega a la presidencia de Colombia por segunda vez, bajo la promesa de una paz estable y duradera.
El plan de gobierno de Juan Manuel Santos en su segundo periodo presidencial busca la configuración de un momento de tránsito que sería el posconflicto, es decir, la puesta en marcha de los acuerdos pactados con la guerrilla. Asumir que este gobierno era responsable de propiciar las condiciones para transitar del conflicto armado hacia una cultura de paz implicaba preguntarse por el papel de la educación en la configuración de prácticas culturales que aporten un estado de paz.

En cumplimiento del principio constitucional de la paz y del artículo 72 de la Ley 115, Ley General de Educación, la cátedra de la paz se reglamenta en el marco del Plan Nacional de Desarrollo Educativo, que da cumplimiento a los mandatos constitucionales y legales frente a los procesos de educación. Es así, como la Ley 1732 del 1 de septiembre del 2014 establece la creación de la cátedra de la paz como asignatura independiente en los planes de estudios de los niveles de educación preescolar, básica y media. El propósito de la cátedra de la paz, de acuerdo con el Decreto 1038 del 25 de mayo del 2015, es el fortalecimiento del tejido social y el cumplimiento de la Constitución Política de 1991, que desarrolla a través de tres ejes centrales: cultura de paz, educación para la paz y desarrollo sostenible.

En el parágrafo 1 del artículo 1 de la ley 1732 de 2014, las universidades en su principio de autonomía universitaria tienen la potestad de decidir de qué manera integrar la cátedra de la paz de acuerdo con la oferta académica, 
los modelos pedagógicos y los planes educativos institucionales. Dadas las condiciones para la creación de la cátedra, en la Universidad Tecnológica de Pereira desde el Departamento de Humanidades la asignatura se plantea como curso optativo para todos los estudiantes de pregrado, con una intensidad de 4 horas semanales y 2 dos créditos académicos.

En el segundo semestre académico del 2015, la asignatura hace la apertura con cinco grupos de estudiantes de pregrado que sumaban a este escenario emergente de formación y reflexión en torno al proceso de paz y a la necesidad de establecer una cultura de paz en garantía del ejercicio de la democracia y de la necesidad de coexistir en la diferencia como consecuencia de la diversidad en todas sus magnitudes.

Al interior de la universidad, la asignatura se concibió como un laboratorio de paz que le daba un lugar preponderante a la participación de los estudiantes en su formación como sujetos políticos capaces de llevar a cabo acciones para la transformación de las prácticas culturales como una posibilidad de transitar hacia una era de posconflicto. En esta apuesta educativa, la memoria en sus dimensiones histórica, familiar y personal juega un papel fundamental en la medida en que permite desentrañar los sentidos y significados ocultos en las nociones del conflicto, la guerra, la convivencia y la paz.

Este despliegue de práctica educativa parte de las pedagogías activas $\mathrm{y}$ críticas para reconocer que la acción formativa es una manera de atravesar las subjetividades de los educandos. Es por eso, que desentrañar en los sentidos y significados de las nociones referentes a la paz tiene un papel protagónico en cuanto el estudiante parte de su mundo de vida para construir, reflexionar y transformar. Aquí el sujeto político en formación es un sujeto de acción que activa otras maneras de ver y leer las realidades y las circunstancias que hoy nos llevan a hablar de la paz.

A lo largo del proyecto de investigación "Formación de sujetos políticos desde una experiencia de educación para la paz", del que deriva este artículo de reflexión, estuvieron presentes las siguientes preguntas: ¿Se forman los estudiantes de la Cátedra de la Paz como sujetos políticos? ¿Cuáles son los despliegues didácticos de la Cátedra de la Paz? Cuestiones que, de alguna manera, nos llevan a revisar en qué medida la asignatura logra vincular al estudiante como sujeto político en un escenario educativo concebido como un laboratorio en el que la exploración, la construcción, la reflexión y la proposición son constituyentes de su propio aprendizaje. Por lo tanto, este texto se centra en analizar la experiencia de una de las estudiantes de la cátedra de la paz, como la posibilidad de leer, en su experiencia, lo que significó el haber pasado por la asignatura.

\section{La paz, una emergencia educativa}

Previo al plebiscito del 2 de octubre de 2016, en el que los colombianos debíamos decidir si apoyábamos el acuerdo final para la terminación del conflicto y la construcción de una paz 
estable $y$ duradera, la historiadora Diana Uribe, hace un llamado a los ciudadanos a reflexionar sobre el proceso de paz, en el que aún nos encontramos. Uribe (2016) ve en esta apuesta una oportunidad para saldar una deuda con el pasado. Más allá de los beneficios que implica para Colombia el hacer esta transición hacia la superación del conflicto armado entre las FARCEP y el Estado, esto significaría un aporte para la humanidad, para lo cual la historiadora arguye que:

Cada vez que los pueblos pasan por un proceso de paz, la humanidad en su totalidad da un paso hacia adelante. No sólo porque la paz nos engrandece como especie, sino porque cada proceso de paz es un aprendizaje que nos da las claves para el siguiente. Así como Irlanda y Suráfrica le están enseñando al mundo cómo superar los odios y la violencia, así también, llegará el día en que Colombia le cuente su historia a los demás para que otros puedan aprender de lo que nosotros hicimos (Uribe, 2016).

No obstante, la paz cuenta con múltiples limitantes, como los grupos políticos que hacen la oposición a este proceso, por medio de dinámicas que aumentan la tensión en la opinión pública. Esto ha ocasionado que los y las colombianas no se hayan cohesionado lo suficiente para apoyar este proceso de paz. De allí que esto denote un 'sentido de fatalidad colectiva' como lo enuncia Uribe (2016) al referirse al individualismo que predomina ante iniciativas de esta magnitud.

Lo anterior indica la emergencia de generar una cultura garante de paz, en el sentido de la cohesión social, el autorreconocimiento de los sujetos en relación con el territorio, nuevas formas de participación política y ciudadana y una construcción de sentidos históricos que intersequen las memorias colectivas. La transformación de las prácticas que conducen a un sentido de fatalidad colectiva es posible desde la educación para la paz, cuyo objeto es llegar hacia la construcción de una cultura de paz (Decreto 1038 de mayo 25 de 2015).

Autores como Dewey (1920), Durkheim (1922) y Runge y Muñoz (2012) parten de la imperfección del hombre para plantear que el humano se hace humano en tanto es educado por el grupo social al que pertenece. La educación, entonces, deviene una necesidad para la vida en sociedad: es una praxis humana en la que convergen prácticas éticas, religiosas, estéticas y políticas. Esta praxis se configura en un hacer que no logra superar la imperfección humana, pero lo humano se presenta ante ello como una tarea, como un proyecto, como una historia, como sujeto de acción (praxis) (Runge y Muñoz, 2012).

\section{La educación como hecho social}

A la sociología de Émile Durkheim se le atribuye una ruptura a la tradición sociológica en la medida en que logra 
esclarecer un método y objeto de estudio que fortaleció, para el momento, la visión de la ciencia social. Esta tiene como objeto de estudio el hecho social, el cual delimita y construye en el primer capítulo de su obra: "Las reglas del método sociológico". Se entiende por el hecho social modos de actuar, de pensar y de sentir que escapan las conciencias individuales, es decir, que están constituidos más allá del individuo (Durkheim, 1895).

Estos modos de actuar, de pensar y de sentir están inmersos en los sistemas culturales de los diversos grupos sociales y que tienen un carácter coercitivo que se transmite a partir de la educación según Durkheim (1895). De manera similar, Dewey (1920) establece una estrecha relación entre educación y comunicación en la transmisión de la cultura:

La sociedad no sólo continúa existiendo por la transmisión, por la comunicación, sino que puede decirse muy bien que existe en la transmisión y en la comunicación. Hay más que un vínculo verbal entre las palabras común, comunidad y comunicación.

Los hombres viven en una comunidad por virtud de las cosas que tienen en común; y la comunicación es el modo en que llegan a poseer cosas en común. (Dewey, 1920, p. 16).

En este sentido, los hechos sociales enmarcados en los modos de actuar, de pensar y de sentir, que son comunes a un grupo humano, son transmitidos desde la comunicación, de tal manera que es posible afirmar en términos de Dewey (1920) "que no sólo la vida social es idéntica a la comunicación (y por lo tanto toda vida social auténtica) es educativa (p.16).

El ser humano no nace preparado para la vida social y, en esa medida, en su tránsito por el mundo, el individuo logra vincularse a un conjunto de prácticas constituidas en el seno de una sociedad. De hecho, cuando Durkheim (1895) se refiere al hecho social, en él se da por sentado que es algo que ya está constituido y de lo que el sujeto no participa en el momento en que se vincula a la sociedad.

En ese orden de ideas, el ser humano al ser el más frágil del reino animal, necesita estar bajo un estado de tutela, que incluso le permita adquirir las habilidades para garantizar su subsistencia (Dewey, 1920). Asimismo, Durkheim (1922) plantea que "la educación es la acción ejercida por las generaciones adultas sobre aquellas que no han alcanzado todavía el grado de madurez necesario para la vida social" (p.53).

\section{La educación en cuanto a praxis}

Entender la educación como la acción que posibilita la transmisión de los tejidos de la cultura es ubicarla al mismo tiempo en una práctica social y humana, que está enmarcada en las dinámicas del hecho social en cuanto su misión responde a formas de actuar, de pensar y de sentir en torno a la vinculación de 
los individuos a la vida social. La acción educativa es asimismo una oportunidad de renovación de la vida humana según Dewey (1920).

La vida desde una perspectiva biológica y antropológica es un constante proceso de renovación. Los seres vivos logran renovarse por medio de la reproducción biológica, mientras que la especie humana alcanza su renovación por medio de la educación, cuya misión es la transmisión de todo lo que se halla inmerso en la vida social que abarca de manera amplia costumbres, instituciones, creencias, victorias, derrotas, ocio y ocupación desde la perspectiva de Dewey (1920).

Runge y Muñoz (2012) se paran desde la perspectiva alemana de Dietrich Benner para desarrollar una perspectiva de la educación como praxis que no es ajena a las relaciones entre la sociedad y la cultura. Por esta razón, plantean a modo de apertura que la praxis es un fenómeno antropológico, y no biológico, si se considera que es un hacer humano que transforma lo humano mismo.

En consecuencia, la educación en cuanto a praxis significa la humanización del hombre que se hace humano a partir de lo que hace: "(...) el ser humano, en tanto ser imperfecto, es la única criatura necesitada y capaz de educación" (Runge y Muñoz, 2012, p.80). Zambrano (2002) afirma que la educación busca el desprendimiento de la condición de animalidad que le es propia al mamífero humano, de tal manera, entonces, que la educación puede leerse desde su dimensión (1) axiológica, en cuanto al educar al otro sobre la base de criar, enseñar y formar; (2) práctica, bajo el principio del valor o el patrón cultural.

\section{La educación en su acepción de lo político}

Rungey Peña(2012) retoman de la teoría de "Pedagogía General" de Benner (1996) seis praxis fundamentales en la vida humana que son transversales a la libertad, la historicidad y el lenguaje. Estas seis praxis se configuran en política, pedagogía, ética, trabajo, religión y arte. Estas praxis resultantes de tres situaciones encaminan a los sujetos a un hacer para la subsistencia (trabajo), para la coexistencia (política, ética) y para su condición humana de finitud (pedagogía, religión y arte).

Si se considera que toda praxis educativa es al mismo tiempo una interacción social, cultural y política, esta debe garantizar que los sujetos se formen bajo una concepción del saber y el ser en armonía con el desarrollo del pensamiento crítico y autorreflexivo. Todo esto con miras a que el individuo se forme para confrontar su condición humana en las tres actividades que Arendt (1993) plantea que se dan en la vida humana: labor, trabajo y acción.

A pesar de que la vita activa para Arendt (1993) es el compendio de la labor, el trabajo y la acción, esta última es la condición humana, que se expresa bajo la idea de la pluralidad:

Sin pluralidad no podemos hablar de acción, ya que esta no tiene sentido en soledad. La acción sólo se 
desarrolla ante la presencia de otros, requiere un espacio público en el manifestarse. Por consiguiente, podemos decir que la pluralidad, en realidad, es una condición a priori de la existencia misma de la vida política (Sánchez, 2015, p. 70).

En este orden de ideas, toda praxis educativa como incursión en la sociedad, pero también como la interacción entre otros debe procurar la existencia de un nosotros plural para el reconocimiento de otro que es igual a mí, pero del que disto en cuanto a mi construcción subjetiva. Es decir, cada individuo posee una subjetividad singular e irrepetible. En consonancia con esto, Zambrano (2002) asevera que "un sujeto es alguien que trasciende en su unidad y en el conocimiento de sí mismo; es un yo por oposición a otro yo; es en tú bajo la fórmula del tú + tú + yo + tú + otro=nosotros" (p.190).

\section{La educación para la paz como praxis curativa}

La educación para la paz en Colombia no surge de súbito; de hecho, se constituye en una necesidad de praxis educativa emergente para la superación de un conflicto armado que ha marcado la memoria colectiva de un país, especialmente, en donde el conflicto generó víctimas directas de los enfrentamientos entre El Estado y los grupos insurgentes. En este caso, se habla de una praxis curativa en la medida en que históricamente la cultura política de Colombia no ha reconocido las múltiples opciones políticas como prácticas válidas.
De allí que esta cultura política no ha sido reconocedora del valor político de la pluralidad y la capacidad del disenso en el ejercicio de la ciudadanía. Por esta razón, Martínez (2015) establece como dos de los cuatro ejes transversales a una educación para la paz (1) una real y efectiva formación política y ciudadana en los estudiantes y (2) crear condiciones para que los estudiantes aprendan a manejar sus emociones.

En esta acepción curativa de la educación para la paz, el valor que suscitan ambos ejes transversales tiene relevancia en el contexto colombiano en la medida en que hay una carencia en el saber controlar las pasiones: en el disentir con las construcciones del otro en el debate público. Es decir, hay una emergencia por transformar las prácticas de participación política por prácticas más sanas que no conlleven a la vulneración de los derechos ciudadanos y políticos de las y los colombianos.

\section{Laboratorios de paz: un lugar para la acción en el aula}

La noción de aula que se evoca acá no necesariamente responde a la representación tradicional que de ella se tiene. Por el contrario, es concebida como el escenario que da lugar a la acción para la formación de sujetos políticos. Se opta en pensar el aula de clase como un laboratorio que permite experimentar en función de un pleno y sano ejercicio de la ciudadanía.

Al respecto, Gómez (2015) reflexiona sobre el deber ser de las instituciones educativas en función de las propuestas 
formativas en paz y para ello sugiere, entonces, que los escenarios educativos deben convertirse en laboratorios que construyan una confianza en los ciudadanos en formación con relación a las instituciones. En esa medida, las cátedras de paz al priorizar aspectos como la participación democrática, los Derechos Humanos (DDHH) y el Derecho Internacional Humanitario (DIH) devienen laboratorios en tanto buscan el empoderamiento de los sujetos en proceso de educación para el emprendimiento de acciones que conlleven a la reivindicación de lo institucional.

Asimismo, Martínez (2015) plantea que la escuela se convierte en laboratorio en tanto que procura enseñar a los niños el significado de la participación política desde el convivir con los otros y el ser copartícipe en escenarios como el gobierno escolar. Es decir que la escuela al ser un espacio de socialización lleva a los niños a confrontarse como sujetos desde su mismidad y la otredad, que permite el paso hacia la acción tal como lo plantea Arendt (1993).

\section{De la educación para la paz hacia la pedagogía para paz}

Asumir lo humano como proyecto, tarea, historia y praxis requiere de un nivel de reflexión que posibilite un acercamiento al hombre, a las sociedades y a las culturas. Esto con el propósito de orientar y reorientar las prácticas educativas, haciendo que la construcción de los sujetos sea un proceso más intencionado. La pedagogía emerge en este punto como el conglomerado de saberes que subyacen a las reflexiones de quienes piensan la educación. Estas miradas se nutren de ciencias y disciplinas como la psicología, la antropología, la sociología y la filosofía.

Históricamente, el concepto de pedagogía se ha entendido como un tratado de la educación, este concepto puede ser abordado desde variadas perspectivas. En este caso, se partirá de la praxeología, ciencia o doctrina de la praxis, para establecer una relación dialógica entre la teoría y las praxis educativas (Runge y Muñoz, 2012): una pedagogía orientada praxeológicamente tiene que estar en condiciones de pensar y de dar orientaciones prácticas con respecto a la praxis educativa y, además, poder probar y fundamentar dichos asuntos -lo que dice (p.81). En este sentido, la pedagogía surge como una forma de reflexión sistemática que le permite a los pensadores (pedagogos) responderse a preguntas como: ¿Cuál es la forma de vida que se le va a presentar de un modo sistemático a las nuevas generaciones, qué se les va a presentar, cómo se les va a educar, para qué se les va a educar? (p.90). Este tipo de cuestionamientos no tuvieron lugar hasta la modernidad, pues la educación no se concebía como un proceso sistemático.

\section{Pedagogía para la paz, un acercamiento praxeológico}

Una mirada praxeológica de la pedagogía para la paz propende por la comprensión de las realidades y los contextos para la transformación de las prácticas que promueven la violencia directa, cultural y estructural. Al mismo 
tiempo, esta perspectiva se circunscribe en una pedagogía crítica que piensa al educando como un sujeto de acción. Ramírez (2008) argumenta que:

De igual manera, asumir este paradigma constituye un punto de partida que conduce a que la escuela interiorice el marco político de la educación, es decir, este paradigma es una base para que el sistema educativo, en su conjunto, fortalezca la crítica sobre las formas de construcción del conocimiento y sobre las maneras en que ese conocimiento se convierte en fuerza social (p.109).

En esta pedagogía, la praxis educativa se configura en un hacer que procura la participación social, la comunicación horizontal entre los diferentes actores que integran los estamentos, la significación de los imaginarios simbólicos, la humanización de los procesos educativos, la contextualización del proceso educativo y la transformación de la realidad social (Ramírez, 2008). Estas acciones, aunque se enuncian pensando en cualquier proceso educativo, tienen relevancia en una educación para la paz. El papel que cumple la pedagogía en este punto es contextualizar a nivel micro y macrosocial las necesidades que las comunidades tienen para acercarse un poco más una cultura de paz.

El 19 de noviembre de 2015, el diario El Tiempo publica un fragmento de la conferencia que el maestro
Estanislao Zuleta orientó en 1989 al grupo guerrillero M-19. El filósofo parte de reconocer los vericuetos de la democracia para evocar la emergente necesidad de diálogo y de emprender acciones para una democracia realmente participativa y plural en sus debates:

La dificultad crece,
también desde luego,
porque sociedades muy
injustas en las que existe no
solamente una distribución
aberrante de los ingresos y
de la riqueza, sino también
en la que existen toda
clase de injusticias, son
sociedades que se suelen
llamar "democráticas",
refiriéndose con ello a unos
cuantos procedimientos,
como, por ejemplo, los
procedimientos electorales,
por medio de los cuales
se nombran presidentes y
congresos, reduciendo la
democracia a un mecanismo
procedimental (El Tiempo,
19 de noviembre de 2015).

Una cultura de paz busca que cada vez se vayan generando prácticas enmarcadas en la participación política en la que los ciudadanos se constituyan a sí mismos como sujetos políticos, como agentes en la construcción de lo público. Por lo tanto, una democracia que parta del pluralismo como principio es dialogante. En ese orden de ideas, Estanislao Zuleta plantea que:

Tenemos, pues, que el diálogoesquizáselelemento más importante de la vida 
de la humanidad de hoy; es una necesidad. Ahora la humanidad, al igual que en épocas anteriores en que enfrentó graves amenazas, guardadas sus proporciones y diferencias, tiene que inventar el diálogo también para sobrevivir, porque no la va a destruir ningún enemigo externo, sino ella misma si no aprende a dialogar y a concertar (El Tiempo, 19 de noviembre de 2015).

\section{La pedagogía para la paz en la} construcción de sujetos históricopolíticos

El empoderamiento político de los educandos para la transformación de sus realidades y contextos próximos es quizá el principal objetivo de una educación para la paz. Desde lo que implica una formación humanística, esto se logra siempre y cuando el sujeto en construcción esté en capacidad de autorreferirse y tomar distancia para enunciar y significar sus propios contextos y los de otros (Londoño, 2016).

La tarea es, entonces, tratar de comprender cómo es que los sujetos significan y resignifican sus relaciones con otros sujetos y con las circunstancias y entornos que van haciendo parte de su vida, en aras de desvelar las dinámicas que subyacen a contextos de aprendizaje, pero que condicionados por lógicas de poder propias, en un caso particular, del sistema educativo, van perfilando subjetividades, modos de ser y estar, de aprender y aprehender la realidad (Londoño, 2016, p.8).

Esta capacidad de poder enunciarse y enunciar a los otros como una emergencia del discurso en la que el sujeto da cuenta de sus vivencias es una posibilidad de ir desvelando sentidos constituyentes de la subjetividad propia como lo plantea Londoño (2016). González de Rey (2007) entiende por sentidos subjetivos la unidad psicológica en desarrollo que integra de forma inseparable procesos simbólicos y emociones, de forma que la emergencia de uno evoca al otro (p.19).

Una pedagogía para la paz no es ajena a los factores y circunstancias a la que los educandos están expuestos; en ese orden de ideas, se procura incentivar a los estudiantes a relatar sus experiencias como una forma de dar cuenta, de tal manera que los sentidos de realidad afloren como una forma del darse cuenta, que se traduce en un despertar de la conciencia de la subjetividad propia. De acuerdo con Londoño (2016), estos tiempos abocan a los sujetos a pensar y pensarse a la luz de la realidad en la que convergen sentidos sociales e históricos. La autora toma la voz de Zemelman (2010) para afirmar que el devenir sujeto o no está en la capacidad de que el individuo pueda leer su presente potencial, abriéndose a nuevas posibilidades de despliegue, 
esto en cuanto a sujeto individualmente historizado.

Esta apuesta pedagógica y didáctica en la que el aula se convierte en el lugar de 'El sujeto y la conciencia histórica' va encaminando a los educandos hacia configuraciones subjetivas: entendidas estas como los sistemas de sentidos subjetivos que van forjando aspectos de la subjetividad individual, de la personalidad propia (González de Rey, 2007). Este acercamiento en el que el sujeto va desarrollando su capacidad autonarrativa debe ponerse en tensión con las narrativas que circundan la vida pública dando paso a que la subjetividad social se exprese.

En este sentido, Diaz (2012) plantea que la subjetividad política se puede entender, en primera instancia, como la acción de reflexividad que realiza el sujeto sobre sí mismo y lo instituido centrándose en el plano de lo público, de lo que es común a todos para desde alli protagonizar instituyentemente la política y político (p.6). En segunda instancia, la subjetividad política puede ser entendida como una expresión de la subjetividad social: Díaz (2012) toma postura desde una perspectiva históricocultural para afirmar que esta se expresa a través de sentidos subjetivos que van generando interrelaciones que constituyen las tramas de la subjetividad política.

Ramírez (2008) al enfatizar la dimensión política de la educación, ve la necesidad de transformar los saberes que se construyen en el aula en fuerza social. Sin una apuesta por la formación de sujetos cognoscentes y de sujetos políticos no es posible llegar a dicha transformación de la realidad. Por lo tanto, centrar la mirada a una educación para la paz que procure el empoderamiento político de los educandos es una posibilidad de desplegar acciones educativas en armonía con el territorio, es reconocer en el estudiante un sujeto con poder de decisión y acción.

\section{Metodología}

Esta investigación se enmarca en un estudio de caso, que según Merriam (1998), Briones (1998), y Dornyei (2007): consiste en delimitar el objeto de estudio, en el ámbito de las ciencias sociales se encarga de los de fenómenos y/o prácticas, que para este caso sería el estudio de una práctica educativa.

La naturaleza del estudio de caso es particularista, heurística y descriptiva (Merriam, 2009). Las muestras que aquí se presentan y se analizan corresponden a la de una entrevista llevada a cabo a una estudiante que cursó la Cátedra de la Paz en la Universidad Tecnológica de Pereira durante el segundo semestre del año lectivo 2015. De acuerdo con Merriam (2009), el análisis de entrevista consiste en un ejercicio hermenéutico que busca desentrañar los significados y sentidos de lo que el sujeto enuncia, para así hallar elementos que contribuyan en el entendimiento de la unidad de estudio.

Así, este ejercicio hermenéutico propende por desvelar los sentidos que suscita la experiencia de Andrea Carvajal en su paso por la Cátedra de la Paz: esto con el objetivo de acercarnos 
a los despliegues didácticos de la asignatura, que de acuerdo con su plan de curso para el año 2015, se configura en un laboratorio de paz que le da gran relevancia a la formación de las y los estudiantes como sujetos políticos.

Andrea fue estudiante de la Cátedra de la Paz mientras cursaba sus estudios en Licenciatura en Comunicación e Informática Educativas. En su paso por la universidad, participó de un proceso de investigación en un semillero de análisis del discurso, fue miembro del grupo de teatro de la universidad y estuvo vinculada a la Ruta Pacífica de las Mujeres. Por lo tanto, en la entrevista nos permitió un diálogo en el que nos permitía ver la lectura que hacía como estudiante, como docente en formación y como activista de su experiencia de aprendizaje en la asignatura.

\section{Análisis y discusión}

Para el caso de Andrea Carvajal ${ }^{3}$, quien llegó a la Cátedra de la Paz movida por un interés personal, la incidencia de la asignatura está en la posibilidad de poder permear a los educandos, de poder tocar esas sensibilidades que se expresan en la confrontación con las opiniones y experiencias de los otros. Esto se logra en la medida en que se llegue a esos ámbitos personales. De allí, que un primer momento, se busque un autorreconocimiento de los sujetos para identificar cuáles eran esas necesidades educativas del grupo para poder generar un currículo que respondiese a ellas.

3 Pseudónimo usado con el propósito de proteger la identidad de la estudiante.
En el primer momento de cátedra se dieron unas discusiones más desde las experiencias personales subjetivas de cada estudiante, y esa fue la manera de recoger qué era lo que el grupo estaba demandando; entonces nos dimos cuenta de en qué debíamos enfocarnos, para el primer momento era reconocernos, reconocer quiénes éramos, reconocer qué era eso del diálogo, qué era eso de la mediación, qué era eso de la conciliación, pero desde la experiencia, desde poner en discusión temas $y$ debatirlos, reflexionarlos en el aula de clase en la experiencia misma;(...)

Ubicándose la Cátedra de la Paz en una serie de acciones enmarcadas en una educación para la paz, esta debe procurar la existencia de un yo plural, que permita reconocer la diferencia como algo que está presente en la vida social, en toda posibilidad de interacción y asociación. En términos de Zambrano (2002) "un sujeto es alguien que trasciende en su unidad y en el conocimiento de sí mismo; es un yo por oposición a otro yo; es en tú bajo la fórmula del tú + tú + yo + tú + otro=nosotros" (p.190), axioma que cobra sentido en la emergencia de la praxis educativa.

$A$ veces se tocaban temas muy sensibles, y que levantaban reacciones 
fuertes entre los estudiantes; por ejemplo la violencia hacia las mujeres una vez se tocó y alguien dijo como "no, es que hay mujeres a las que les gusta que las violenten" y pues obviamente levantó la sensibilidad de nosotras, $y$ sí hubo un malestar, pero siempre lo que... Liliana [la docente de la cátedra de la paz] repetía mucho esta frase: "a mí me gusta asumir la terapia de choque, a mí me gusta mostrarles a ustedes los casos de esa manera, que les toquen sensibilidades, porque hay que llegar al componente emocional para acercar esos casos"; otros temas fueron los del paramilitarismo, también, fueron fuertes, y asi había diferentes perspectivas que a veces tocaban... incrementaban mucho el tono emocional y la gente se iba apasionando, entonces sí...

En ese orden de ideas, Andrea concibe la Cátedra de la Paz como un escenario en el que confluyen una serie de acciones que propician procesos de subjetivación, que parten del autorreconocimiento de los educandos en sus dimensiones históricas con respecto a los ámbitos (micro)contextuales. Esto antes de aproximarse a una comprensión del sujeto político en la vida pública. Londoño (2016) desde la perspectiva de Zemelman (2010) establece que el devenir sujeto está condicionado a la capacidad de poder (re)significar los contextos propios y los de otros, de poder enunciar y enunciarse a partir de diversas situaciones, que llevan a la emergencia de sentidos subjetivos, de sentidos historizantes. De allí, que el sujeto político sea simultáneamente un sujeto historizado:

Subjetividades, creo que es importante; resolución de conflictos, y también formación histórica $y$ política. Pero yo creo que a eso apunta la cátedra, pero primero se interesa por lo que se da en términos de lo micro, de lo contextual, de cada estudiante. Entonces primero se dan los procesos de subjetivización, se dan los procesos de apropiación para después mirar qué es esto del sujeto político en lo público; creo que hacia allá va la cátedra.

Estos despliegues subjetivos, en los que se recurre en algunas ocasiones a las memorias individuales desde los relatos autobiográficos y a las memorias colectivas desde las lecturas de los contextos, avocan también a procesos de simbolización, que a la vez van generando configuraciones en el sujeto. González de Rey (2007) define las configuraciones subjetivas como una red de sentidos subjetivos que van surgiendo a medida que el individuo va generando relaciones significativas. Estos sentidos subjetivos son el resultado de las unidades psicológicas que interactúan como simbiosis entre 
procesos simbólicos y emociones: sentidos que están en una incesante interacción entre sí, es decir (González de Rey, 2007).

En términos de las
maneras de desarrollo,
hubo un trabajo simbólico
muy fuerte; siempre
los tres momentos más
significativos que yo
recuerde, primero la toma,
la toma que es como el
cierre de la cátedra, para
ese momento nosotros
trabajamos mucho desde el
cuerpo, desde el territorio,
desde las expresiones
artísticas...

Esta posibilidad de poder simbolizar experiencias, de poder relatar a través de otras formas de codificación se circunscribe en una noción del aula de clase como un laboratorio y de la educación como una praxis curativa. Es en este punto donde las expresiones artísticas aparecen integrando didácticas y estrategias que propician espacios de interacción, creación y transformación. Martínez (2015) propone la Cátedra de la Paz como un espacio real de formación política, pero también como el escenario en el que el estudiante aprende a manejar sus emociones.

Andrea,comoestudiantedelaasignatura, relata cómo la profesora propuso ejercicios en los que se involucraban el vídeo y la fotografía como medios que posibilitaban la expresión, para ello realizaron entrevistas, filminutos y relatos fotográficos, rompiendo con los paradigmas del texto lingüístico y lineal, dando paso a otras vías de expresión que materializan relatos y discursos. En ese sentido, ella genera una claridad sobre qué es el filminuto:
Un "filminuto" es en un formato más corto (...) lo que tiene el "filminuto" es que te cuenta una historia que puede ser por medio de un dramatizado, por medio de ilustraciones, tú decides cómo hacer esa narrativa, y da cuenta de ese relato. Ese es el "filminuto".

Estos ejercicios, más que buscar un dominio de las técnicas audiovisuales, se proponía darle un lugar esencial a la expresividad de los educandos: consistía más en aprovechar al máximo los recursos de fácil acceso como el celular, creando situaciones de aprendizaje, situadas en momentos pedagógicos, que Zambrano (2002) describe como el momento en el que el educando acude al saber para así explorar con el educador otros caminos. El momento pedagógico es una reflexión axiológica en torno al saber y al saber hacer, es una práctica política en la medida en que genera relaciones de tensión entre el estudiante y el docente, el grado de tensión es proporcional al grado de autonomía otorgado al estudiante. Por lo tanto, buscar que los educandos se acerquen a nuevas expresividades desde el hacer, además de ser una puesta de las pedagogías activas, es una apuesta política que propende por relaciones más simétricas en los procesos de Enseñanza-Aprendizaje. 
No. Sí, digamos se tomaba el celular y con el celular de cada uno porque como actualmente todo el mundo tiene acceso a ese tipo de cámaras, con el celular, o si tenían una cámara digital, no importaba tanto como ese aspecto técnico, más bien la expresividad, más bien la discusión, también, se hicieron las fotografias, pero escribía un texto que diera cuenta de la exposición, de la colección de fotografías, entonces ahi se enfocaba más el proceso.

Andrea, en consecuencia, valora estos despliegues didácticos y pedagógicos como fundamentales en la medida en que le da un lugar en el aprendizaje a los lenguajes que son cotidianos para los jóvenes:

A mi me parecieron fundamentales. Porque, primero implicaron que hubiese una etapa teórica, que hubiese una etapa de discusión, que hubiese una etapa de debate, para después poderlo poner en escena, poderlo expresar a través de otros lenguajes, no solamente el escrito, no solamente el argumentativo, sino otras cosas que están más cercanas son más cercanas a los discursos que actualmente manejamos los jóvenes.
La cátedra de la paz se circunscribe en una visión activa de la pedagogía, en la que el aprendiz es un agente en su proceso de aprendizaje, rompiendo con la premisa de la educación tradicional que concebía al aprendiz como un tabula rasa. De allí, que se parte de nociones previas, en este caso de la paz y la política, para generar esquemas cognitivos que den lugar a la apropiación de temas que conciernen a la cátedra en sí. Los estudiantes también se enfrentaron a la polisemia de la paz, para llegar una noción de paz en la que el conflicto está presente, no como limitación, sino como algo que es inherente a la misma condición humana:

Yo creo que lo que más la caracteriza es que se vuelve vivencial, atraviesa... bueno, para quien asumía porque no nos vamos a decir mentiras, no todo mundo asume los procesos de la misma manera, y no a todo el mundo lo afectan en la misma magnitud, pero yo diría que lo que ofrece la Cátedra de la Paz, lo que ofrecía en ese momento eran herramientas para la vida, herramientas para conciliar conflictos, otras visiones del mundo, otras maneras de entender también la paz, porque estamos muy acostumbrados a ver la paz como un estado de tranquilidad, de uniformidad, etc., donde pareciera que no 
La cátedra de la paz: un escenario emergente de praxis educativa en la Universidad Tecnológica de Pereira

se da el conflicto, y a lo que llegábamos y a las conclusiones a las que llegábamos era que no necesariamente la paz se construye de esa manera; esa es una forma, esa es una noción, pero, hay otras; hay otra en la que sí se acepta el conflicto, es verdad que tenemos visiones distintas, pero qué bueno que podamos sentarnos a hablar, a entablar y a poner en escena nuestras nociones, nuestras ideologías, nuestras posturas, sin que por eso nos vayamos a matar, o sin que por eso yo vaya a entrar a agredir a la otra persona, entonces creo que se puede definir en esa frase: herramientas para la vida.

Si bien la misión de la Cátedra de la Paz en cuanto a la formación de sujetos políticos es pretensiosa, la relevancia que cobra la formación política en esta es la que posibilita despertar esas sensibilidades políticas que han estado adormecidas y que van aflorando en la medida en que el sujeto se confronta con otros individuos, con otras experiencias $\mathrm{y}$ con otros discursos.

En su acepción misional, este escenario podría estar cercano a lo propuesto por Gómez (2015) y Martínez (2015) que enfatiza en que las cátedras de la paz son laboratorios en los que los educandos aprenden de participación política conviviendo con otros, donde aprenden, además valores como la confianza y el sentido más político de vivir en comunidad al que Arendt (1993) denomina acción, cuya condición humana es la pluralidad, siendo esta misma la condición humana en sí. Es decir, la cátedra de la paz evoca la idea del laboratorio en el sentido metafórico y etimológico de la palabra, que es el lugar donde la acción toma lugar, acá la acción se entiende en su dimensión política: la cátedra se constituye, entonces, en un laboratorio de formación de sujetos políticos.

En su relato, Andrea nos da indicios de que este proceso educativo activa sensibilidades políticas en los educandos, que pueden ser trasladadas a otros escenarios de interacción, de tal manera que esos aprendizajes logren articularse a otros procesos sociales y comunitarios:

AD: ¿Usted cree que esta cátedra en particular, y este estilo de trabajo, ayudan en la formación política de ustedes como jóvenes?

JR: Yo creo que sí. Yo creo que si porque forma o trata de poner en lo cotidiano la noción de política y de lo político, entonces entender que... por ejemplo hay estudiantes que tenían la idea de la política sólo la politiquería, o sólo con respecto a los políticos, y ahi lo que se discutía era "pero es que mire que si usted asume un proceso en público, usted se asume 
como sujeto colectivo, usted también está haciendo un ejercicio político, sólo que no es igual a esta otra noción que usted tenía" $y$ "Aaaah... ya..." eso entraba en conflicto con las ideas previas que tenían los estudiantes, pero ya quien quiera ampliar más las nociones o quien quiera conocer más, creo que sí debe ir a otros escenarios y a otras... remitirse a autores, formarse de otras maneras, pero esto sí era una semilla, un primer paso hacia esa formación política.

\section{Conclusiones}

La Cátedra de la Paz constituye una emergencia de praxis educativa en la Universidad Tecnológica de Pereira, una vez que la Ley 1732 del 1 de septiembre de 2014 y el Decreto 1038 del 25 de mayo de 2015 le dan legitimidad. Su necesidad se expresa al priorizar la asignatura como un laboratorio que procura la formación de sujetos políticos. Es por eso, que esta apuesta pedagógica busca al mismo tiempo despertar en los estudiantes una sensibilidad política, una vinculación con los intereses a las diferentes formas en las que se expresan las ciudadanías en Colombia, sobre todo en torno a la paz como hecho.

Está presente la pregunta de si en la Cátedra de la Paz de la UTP se forman sujetos políticos o no. Quizá la pregunta sea pretensiosa; sin embargo, el relato de
Andrea nos devela que este laboratorio de paz contribuye, de alguna manera, a la formación de sujetos políticos: algunos llegan con una conciencia política más desarrollada frente al tema y otros quizá llegan buscando saciar esa necesidad de reconocer que en Colombia ha habido un Conflicto Armado entre el Gobierno $\mathrm{y}$ las fuerzas insurgentes.

La entrevista con Andrea nos acerca a pensar que, si bien un semestre no es suficiente para el devenir de sujetos políticos, la incidencia de la Cátedra de la Paz radica en el despertar de la conciencia política de los educandos que se van acercando, a través de los ejercicios planteados, a desvelar las realidades circundantes en su relación con el territorio (local, regional y nacional). Es un escenario de confrontación donde el educando pone en común sus opiniones, quizá suscitando reacciones no esperadas en sus compañeros, pero en eso consiste también el propiciar situaciones de aprendizaje para una cultura de paz: aprender a convivir en el disenso.

La asignatura busca también activar la subjetividad política desde las memorias (individuales, colectivas e históricas) generando sentidos históricos: esto bajo una concepción de que el sujeto político es al mismo tiempo un sujeto histórico, un sujeto historizado. Esto les permite a los estudiantes hacer lecturas de la paz como hechos o anhelos que han atravesado nuestras historias de vidas. Activar las memorias significa sembrar un deseo de transformación para un mejor tránsito por los espacios compartidos, para una mejor práctica de la política en todas sus acepciones. 
La Cátedra de la Paz se configura como un laboratorio en el que el hacer juega un papel preponderante y esta es la mayor apuesta didáctica de la asignatura como lo evidenciamos en la entrevista con Andrea, en la medida en que logra tocar las sensibilidades de los estudiantes que son co-constructores de este escenario de aprendizaje. Es por eso, que la profesora parte de la interacción con los educandos para identificar las necesidades y expectativas que se tienen frente a la asignatura, de tal manera que la propuesta educativa logre cumplir su propósito, que es explorar para reflexionar y reflexionar para proponer/ transformar.

De acuerdo con la experiencia de la estudiante, este laboratorio lo percibe como un espacio vivencial que logra atravesar las diferentes subjetividades que concurren este espacio. La manera en la que se construyen los saberes busca que en ella haya una multiplicidad de expresiones y formatos, lo cual procura que desde la indagación y la creación los estudiantes lleguen a niveles de reflexión frente a hechos históricos y sociales. No se busca formar sujetos que dominen las técnicas de la fotografía, el vídeo, el cine y la crónica, se busca que a través de estas narrativas los educandos se expresen y relaten. Es decir, se constituyen en medios para llegar a expresar niveles de aprendizaje y aprehensión de las realidades.

\section{Referencias bibliográficas}

Arendt, H. (1993). La condición Humana (Trad. Ramón Gil Novales). Barcelona: Paidós.
Arias, D. (19 de febrero de 2015). 'El diálogo es hoy una necesidad de la humanidad': Estanislao Zuleta. El Tiempo. Recuperado de http://www.eltiempo.com/archivo/documento/ CMS-15274538

Briones, G. (1998). Capítulo 2: Las investigaciones cualitativas. La investigación social y educativa (63-70). Santafé de Bogotá: TM Editores.

Congreso de Colombia. Ley No. 1732. Septiembre 1 de 2014. Por la cual se establece la cátedra de la paz en todas las instituciones educativas del país" Tomado el 2 de agosto de 2015 de http://wsp.presidencia. gov.co/Normativa/Leyes/Documents/ LEY\%201732\%20DEL\%2001\%20DE\%20 SEPTIEMBRE\%20DE\%202014.pdf

Departamento de Humanidades UTP (2015). Cátedra de la Paz (Microcurrículo). Recuperado de http://media.utp.edu.co/ humanidades-idiomas/archivos/Programa $\% 20$ CATEDRA\%20DE\%20PAZ\%202015-2.pdf

Dewey (1920/1995). Democracia y educación. Madrid: Ediciones Morata.

Dornyei, Z (2007). Qualitative, quantitative, and mixed methods research. Research methods in applied linguistics (24-47). Spain: Oxford University Press.

Díaz, Á. (2012). Devenir subjetividad política: Un punto de referencia sobre el sujeto politico. Pereira, Colombia: Editorial UTP.

Durkheim, É. (1922/1973). Educación y sociología. Barcelona: Ediciones Península.

Durkheim, É. (1895/2002). Las reglas del método sociológico. México DF: Fondo de la Cultura Económica. 
Gómez, E. (2015). Reflexiones para una pedagogía para la paz. En Hernández, I (Editora), Ruta Maestra (pp. 65-70). Bogotá, DC: Santillana S.A.S.

González de Rey, F. (2007). Posmodernidad y subjetividad: distorsiones y mitos. Revista de Ciencias Humanas, 37(1), 7-25.

Londoño, C.M. (2016). Pensar la evaluación como un nivel de darse cuenta. En Á. Díaz(Ed.), Evaluación o calificación en humanidades/Seis experiencias en contexto universitario (pp.719). Pereira, Colombia: Editorial UTP.

Martínez, J. (2015). ¿Cuál es el papel de la educación en la construcción de una Colombia en Paz? En Hernández, I (Editora), Ruta Maestra (pp. 78-81).

Merriam, S. (1998). Case studies as qualitative research. Qualitative Research and Case Study Applications in Education (27-43). San Francisco: Jossey-Bass Publishers.

Merriam, S. (2009). Qualitative research. A guide to design and implementation. San

Francisco: Jossey-Bass.

Ministerio de Educación Nacional. Decreto 1038 de mayo 25 de 2015. Por el cual se reglamenta la Cátedra de la Paz. Tomado el 2 de agosto de 2015 de http://wp.presidencia.gov.co/ sitios/normativa/decretos/2015/Decretos2015/ DECRETO\%201038\%20DEL\%2025\%20 DE\%20MAYO\%20DE\%202015.pdf

Naranjo, J. (2015). Los niños piensan la paz. Bogotá: Banco de la República/Subgerencia Cultural.

Ramírez, R. (2008). La pedagogía crítica/Una manera ética de generar procesos educativos. Folios, 28(2). 108-119.
Runge, A., \&amp; Muñoz, D., (2012). "Pedagogía y praxis (práctica) educativa o educación. De nuevo: una diferencia necesaria". Revista Latinoamericana de Estudios Educativos, 8(2), 75-96.

Uribe, D. [Forjando Paz]. (19 de junio de 2016). Dejemos de matarnos [Archivo vídeo]. Recuperado de https:/www.youtube.com/ watch? $\mathrm{v}=\mathrm{kVw}$ _I9KItwc $\& \mathrm{t}=4 \mathrm{~s}$

Zambrano, A. (2002). Los hilos de la palabra: Pedagogía y Didáctica. Colombia: Cooperativa Editorial Magisterio. 